\title{
Espaços públicos, participação e clientelismo: um estudo de caso sobre o orçamento participativo em Barra Mansa, Rio de Janeiro
}

\author{
Angela Vieira Neves \\ Universidade Federal Fluminense (UFF)
}

\begin{abstract}
Espaços públicos, participação e clientelismo: um estudo de caso sobre o orçamento participativo em Barra Mansa, Rio de Janeiro

Resumo: Este artigo tem como objetivo analisar os desafios dos espaços públicos na cultura política brasileira, para tanto é apresentado um estudo de caso sobre o orçamento participativo no município de Barra Mansa, Rio de Janeiro. O texto está dividido em três seções, a primeira dedicada ao trato dos desafios das experiências de orçamento participativo na cultura política brasileira, enquanto a segunda analisa a experiência Barra Mansa. Por último são mencionados os conflitos gerados entre o legislativo municipal e a implementação dos espaços participativos. No segmento, relatam-se alguns dos efeitos políticos constatados: a resistência dos vereadores frente ao OP, tensionando a cultura política fundada no favor; a perda de poder político do vereador, por sentir-se prejudicado, ameaçado e desprestigiado pelo Executivo; a disputa política criada entre os vereadores e os representantes da sociedade civil - já que o OP possibilitou a formação de novas lideranças locais.
\end{abstract}

Palavras-chave: participação, espaço público, política e democracia.

\section{Public Spaces, Participation and Clientelism: a Case Study About the Participative Budget in Barra Mansa, Rio de Janeiro}

Abstract: The object of this article is to analyze the challenges of public spaces in Brazilian political culture. To do so, it presents a case study about the participatory budget process in the municipality of Barra Mansa, Rio de Janeiro. The text is divided in three sections. The first is dedicated to the challenges of the participatory budget experiences in the Brazilian political culture, while the second analyzes the process in Barra Mansa. Finally, it presents the conflicts generated between the municipal legislature and the implementation of participatory spaces. In the segment, some of the political effects found are reported including: the resistance of city councilmen to the $\mathrm{PB}$, which creates tension with the supporters of the political culture that support this process; the loss of political power of city council representatives, who feel harmed, threatened and a loss of prestige in relation to the executive branch; and the political dispute between city council representatives and representatives of civil society - given that the PB allows the formation of new local leaders. Key words: participation, public space, politics and democracy.

Recebido em 16.04.07. Aprovado em 27.06.2007. 


\section{Introdução}

Este artigo tem como objetivo ${ }^{1}$ marcar o campo de disputa entre os projetos neoliberal e democrático-popular, procurando analisar de que maneira esses novos espaços públicos participativos sofrem riscos e desafios ao seu potencial democratizador ao emergirem no contexto dos anos 1990. Esses limites são colocados pela cultura política dominante com traços herdados e já bem conhecidos da história brasileira, tais como o clientelismo na política.

$\mathrm{O}$ aparecimento de novos instrumentos de gestão ${ }^{2}$, após a Constituição de 1988 - como é o caso do Orçamento Participativo - mostra a tentativa de construção de uma cultura pública que possibilite novos direitos e cidadania.

A Constituição Federal de 1988 - conhecida como Constituição-Cidadã - representou um divisor de águas nesse contexto, ao reafirmar instrumentos importantes para a democratização, mostrando-se decisiva para a publicização do orçamento e do Estado. Pela primeira vez, uma constituição retrata a importância da construção de um Estado Democrático de Direito. Nesse cenário em que a Constituição é promulgada são feitas alterações importantes nos marcos da construção de um Estado de Direito e de um processo democrático, no qual municípios ${ }^{3}$ são criados e novos instrumentos de gestão, como os conselhos gestores e o OP, ampliaram-se. Alguns municípios com experiências democráticas implantaram o orçamento participativo ${ }^{4}$ após a vitória da esquerda, em particular, durante os anos 1990, com o objetivo de possibilitar a participação da sociedade civil nas decisões do Estado.

É nos marcos da hegemonia do projeto neoliberal - particularmente no governo Collor de Mello, em 1989 - que, coincidentemente, esses espaços públicos participativos se multiplicaram. A proliferação do OP emerge nesse cenário de "confluência perversa", nos termos de Dagnino (2004), entre projetos que disputam e deslocam o significado democratizador e politizador da sociedade civil.

\section{Espaço público e participação: desafios da democracia participativa na cultura política brasileira}

Nessa aposta democrática participativa, após os anos 1980, surgem, na década de 1990, os cha- mados públicos participativos, os quais, nos termos de Avritzer, consolidaram-se e constituíram-se na mais recente forma de inovação democrática e política na tentativa de construir novos espaços públicos, radicalizando a democracia. Esses novos espaços públicos se contrapõem à imbricada relação entre público e privado tão debatido na história da sociedade brasileira. O conceito de público participativo foi elaborado por Avritzer e Wampler (2004, p. 215) e compreende "cidadãos organizados que buscam superar a exclusão social e política por meio da deliberação pública, promoção de transparência e responsabilização (accountability) e da implementação de suas preferências políticas." Os orçamentos participativos são exemplos notórios desse aparecimento, buscando nova hegemonia, que se oponha ao Projeto Neoliberal, e evidenciando a disputa entre interesses públicos e privados.

O orçamento participativo - como mostra a literatura surgiu como projeto político do Partido dos Trabalhadores (PT) em Porto Alegre e tornou-se marca da gestão petista. A participação popular tornou-se referência na implementação desse projeto político para outros partidos, bem como objeto de estudo de diferentes analistas. Confirmando essa opinião, Dias (2002) diz que o despertar do fenômeno do OP confunde-se com a ascensão política do PT naquela cidade. Em razão disso, investiu-se na análise de seus efeitos para a cidade - em particular, na de Porto Alegre, onde a experiência tem tido êxito há anos e tornou-se modelo para outros municípios em que não há essa tradição.

No dizer de Ribeiro e Grazia (2002, p. 40), “o OP encontra-se orientado para o alcance de conquistas institucionais e para a transformação da cultura política." Embora a marca da 'participação popular' do PT venha surgindo, ao longo dos últimos anos, como novo modo de exercer a política, os obstáculos à construção da democracia presente na cultura política local evidenciam a necessidade de cuidado ao se reproduzir o modelo de Porto Alegre em municípios com diferentes tradições na cultura política. Como é sabido, o OP em Porto Alegre propiciou o processo de democratização do Estado ao introduzir mecanismos deliberativos de alocação das decisões sobre os recursos públicos na cidade e alterando substancialmente as formas tradicionais da cultura política. No entanto, não é regra que outros municípios, ao implementarem o OP, tenham conseguido amenizar esse impacto sobre a cultura política dominante com 
traços já bem conhecidos na sociedade brasileira: fisiologismo, clientelismo nepotismo e corrupção.

Há uma extensa literatura sobre o $\mathrm{OP}^{5}$ que, analisada por diferentes autores, possibilita o debate de várias questões. Nela há um discurso que chamei de apologético e idealizante quando da implementação do OP em Porto Alegre, discurso que foi propagado na literatura pelos formuladores do programa do OP, ligados à intelectualidade petista. Esses afirmaram que o OP rompe com a cultura clientelista, cria nova cultura política e representa um modo inédito de exercer a política, com forte potencial democratizador, e provoca impacto na cultura política até então dominante.

Navarro (AVRITZER; NAVARRO, 2003) chama a atenção para e critica o tom idealizante dessa chamada efervescência participativa presente no debate sobre o OP. No contexto do processo de democratização - em especial, após os anos 1990, com o projeto neoliberal - seria, no mínimo, perigoso afirmar que o OP consegue 'romper', 'superar' a política clientelista. Negligencia-se assim a disputa entre distintos projetos pela hegemonia na política bem como os deslocamentos da participação. O orçamento participativo, portanto, consolida-se na literatura nos anos 1990 a partir de alguns desafios: a) qualifica a democracia representativa; b) tem efeito distributivo - a justiça distributiva é um dos elementos para a constituição da inversão de prioridades, buscando a inclusão social dos subalternos; c) baseia-se no princípio da autonomia e na participação popular, procurando construir novas gramáticas na política (um novo modo de exercer a política).

Queremos chamar a atenção é para a perda desse espaço público, onde o projeto neoliberal não só instrumentaliza as ações coletivas, mas também desmobiliza a sociedade civil e desconstrói direitos até então conquistados pelas classes populares.

\section{A experiência de Barra Mansa: desafios na construção de uma nova cultura política}

A idéia inicial de implementar o OP em Barra Mansa foi fruto de um seminário interno. Quando o PT venceu as eleições de 1996 - fato inédito na história do município -, a idéia pôde ser realizada pela experiência do programa do OP com a meta de "democratização da administração pública numa perspectiva popular democrática. A transparência da gestão associada ao combate à corrupção foram os temas e discursos ideo-políticos revelados pelo governo" (JORNAL DO OP, 1998).

O município de Barra Mansa iniciou a implantação do OP simultaneamente a do estado do Rio de Janeiro, em contexto político partidário de alianças. Em Barra Mansa, sob a gestão do PT e em aliança com o PPS, a experiência do OP durou de 1997 a 2000, tempo do exercício de um único mandato do PT.
O PT, ao assumir o governo, convocou a população a 'participar do OP' para poder decidir no tocante à gestão da cidade, no combate à corrupção e no conhecimento das contas públicas: "O orçamento público municipal nunca mais será feito às portas fechadas, entre o Secretário de Fazenda e o Prefeito Municipal. Ele busca democracia e transparência na gestão municipal" (BARRA MANSA, 2000).

Depoimentos e matérias de jornal corroboram a nossa análise de que o OP em Barra Mansa - por ser cidade de médio porte e em desenvolvimento local, além de ter forte tradição cultural arraigada ao clientelismo político - deveria representar uma 'ruptura na cultura política no município ${ }^{6}$.'

Essa questão está citada no Manual do Orçamento Participativo de Barra Mansa:

O discurso do prefeito se baseava na 'inovação democrática' do programa, na 'vontade política', na 'transparência' na condução dos investimentos e gastos públicos. O slogan da campanha de governo em 1996 era 'é tempo de mudança'. Assim, 'participar é o único caminho para construir a cidade que todos desejamos.' A proposta do governo 'tinha como tema um governo democrático e popular', uma outra forma de se fazer política e definir prioridades, 'rompendo com as práticas tradicionais de troca de favores' (BARRA MANSA, 2000, grifos nossos).

A ênfase na ruptura com tais práticas conservadoras na política eram freqüentes nos discursos políticos e nos documentos oficiais em Barra Mansa. Da mesma forma, o tema está presente na literatura sobre o OP de maneira bastante consensual, afirmando-se a experiência de participação popular como ruptura com o clientelismo e o fisiologismo na política, sendo o OP compreendido como instrumento de co-gestão com o estado no sentido da partilha do poder no orçamento público na busca da democratização radical. Nessa direção, a literatura aponta que o OP consegue romper com o patrimonialismo (FEDOZZI, 1997), e com o clientelismo político pois "O surgimento do OP configura uma nítida ruptura com o clientelismo na política brasileira, principalmente com a tradição política fortemente marcada pelo patrimonialismo e pelo autoritarismo burocrático" (SANCHES, 2002, p. 14, grifos nossos).

A campanha de governo, em 1996, com a coligação 'muda Barra Mansa' tinha no seu discurso político e ideológico a tentativa de evidenciar que a política local era o reflexo das ações controladoras e fisiológicas por parte daqueles que ali dominavam o poder local ${ }^{7}$ de modo hegemônico, como se pode ver no slogan de campanha, ao ressaltar que:

Os ex-prefeitos estão novamente juntos, no que chamamos uma ação entre amigos. Para eles, tanto faz quem vai ganhar a eleição, pois eles vêm divi- 
dindo o poder entre eles próprios há quase 50 anos e o que querem é continuar assim. Chega de coronéis. Muda Barra Mansa! (BARRA MANSA, 1996).

A idealização, a euforia democrática e o discurso apologético do PT visavam à construção de uma cultura política fundamentada no modelo de democracia participativa. Porém, como veremos abaixo, as principais dificuldades na operacionalidade do programa foram aparecendo já no primeiro ano de implantação.

Já no primeiro ano de implantação do OP, encontra-se o discurso político de incentivo à participação, caracterizado como apologético, nas primeiras plenárias do $\mathrm{OP}$, que aconteceram com intensa participação popular.

O movimento de mudar a cidade era o slogan que a prefeitura vislumbrava na implementação do OP. O combate à corrupção, a ruptura com o clientelismo, o fisiologismo e o corporativismo na política e a construção de uma nova cidade foram às tônicas do discurso do governo municipal. Porém, a implementação de um instrumento de inovação democrática na política local fez com que atores mais tradicionais na política, tais como os vereadores e líderes de associações de moradores, mantivessem resistência ao OP.

\section{Conflitos entre a Câmara de Vereadores e o orçamento participativo de Barra Mansa}

No primeiro ano de governo do PT, em 1997, foi feita a entrega da proposta orçamentária elaborada pelo OP na Câmara, o que representou um divisor de águas na confecção da peça orçamentária no município até aquele momento. A prefeita compareceu à Câmara e declarou ${ }^{8}$ :

Hoje é uma data histórica para o município de Barra Mansa, fiz questão de entregar pessoalmente ao poder Legislativo, na pessoa do Presidente, a Proposta Orçamentária para 1998. Assim entendemos existir democracia e transparência entre o Executivo e o Legislativo, nós estamos a serviço da população, pois ela deve ajudar na confecção do Orçamento, em BM tivemos êxito, pois tivemos mais de mil pessoas nas reuniões para realização do Orçamento Participativo, quero ressaltar a participação dos senhores vereadores, fica marcado nos Anais da Casa esse momento histórico.

Por essa razão, a preocupação dos agentes do governo era combater o clientelismo e a corrupção na política. Instaurou-se assim um projeto que buscava iniciar o processo de democratização e o aprofundamento da cidadania, realizada com a participação popular. $\mathrm{O}$ desafio estava colocado com a implantação do OP no município.
Este caminho, o democrático, ajuda na construção de uma nova cultura política, que supera os vícios do autoritarismo, paternalismo, clientelismo e apadrinhamento, na relação governo e sociedade $\mathrm{O}$ sucesso deste projeto inovador para a construção de uma feliz cidade dependerá do esforço, do bom senso, do compromisso, do espírito de luta e solidariedade de todos. Portanto participar é o único recurso para fazer vingar a Cidade que todos merecem ${ }^{9}$.

A busca por transformar a cultura política brasileira também foi destacada por Ribeiro e Grazia (2002, p. 40):

[...] como o orçamento participativo possui uma clara face de projeto, é indispensável valorizar a sua experimentação nos mais diferentes contextos socioeconômicos do país, favorecendo a emergência de práticas progressistas, ainda que embrionárias, em espaços tradicionalmente avessos à participação social. Destas práticas, podem emergir novos aprendizados políticos e envolvimentos em redes de movimentos sociais que permitam maiores ganhos em democracia. Encontram-se em jogo, o OP considerado pleno, os elementos de um potencial partilha do poder, trazendo a promessa de alterações profundas na hierárquica cultura política brasileira.

As primeiras reações e os efeitos na cultura política foram sentidos na implementação do OP já no primeiro ano, ao sofrer fortes resistências e oposições do Legislativo. O predomínio do personalismo e do pragmatismo em detrimento do projeto político-ideológico do partido fez da entrada do PT no Executivo um duplo desafio. Em primeiro lugar, torna-se fundamental neutralizar os traços históricos mais conservadores e perversos à cidadania, e, em segundo lugar, é preciso instaurar um caminho novo associado à própria história do $\mathrm{PT}$ - uma história associada aos Movimentos Sociais ao exercer a política com transparência e participação popular. A clássica forma de representação é questionada quando novo elemento entra na disputa política. $\mathrm{O}$ terreno do conflito entre o Legislativo e o Executivo teve lugar quando houve a quebra na política entre ambos. Isso porque os vereadores estavam acostumados a uma prática política com o Executivo em que se reproduzia o 'favor', os 'pedidos pessoais' para reforçar a sua base eleitoral ${ }^{10}$.

Essa política assistencialista foi quebrada e sofreu tensão com a introdução do OP. Mudar a política, modificar a prática política desses vereadores, diz respeito a repensar seu próprio papel na Câmara. Portanto, diante da possibilidade de construção de uma nova forma de se fazer política, surge o conflito, que foi o limite inicial ao processo de construção de- 
mocrática e de consolidação desse espaço público provocado com o surgimento do OP no município.

A natureza deliberativa do OP vai representar um novo canal de intermediação de interesses da população, além dos dois canais institucionais - o Executivo e o Legislativo. A questão colocada aqui é a da partilha do poder e a possibilidade iniciada pelo OP da construção de nova cultura política. A difícil convivência entre os diferentes atores era de se esperar, pois "encontram-se em jogo, no OP, considerado pleno, os elementos de uma potencial partilha do poder, trazendo a promessa de alterações profundas na hierárquica cultura política brasileira" (RIBEIRO e GRAZIA, 2002, p.40).

A resistência dos parlamentares foi o primeiro efeito surgido da 'tensão' provocada na política em razão do orçamento participativo. Essa resistência estava associada à ameaça de perder o poder político por parte dos parlamentares. Essa questão aparece em várias pesquisas sobre o OP, como em Silva (2001), Santos (2002), Dias (2002) e Avritzer (2002). Concordamos com Pedro Pontual (2000, p. 86), ao afirmar que "a relação com os vereadores é muitas vezes tensa, já que estes perdem a paternidade das obras que passam a ser vistas como conquista da população organizada [...]."

Em síntese, foram verificados alguns efeitos que o OP provocou na cultura política local, dos quais destacamos os relatados a seguir.

a) O primeiro efeito político foi que o OP provocou a resistência dos vereadores como evidência da tensão entre culturas políticas - incitando-os a encontrar novo perfil de seu papel, de sua política. Em outras palavras, significa que o OP inibiu a cultura política mais conservadora exercida por eles no município. A política assistencialista do Legislativo sofreu tensão diante da possibilidade de construção de uma cultura mais participativa e democrática, que é estimulada com o OP.

b) $\mathrm{O}$ segundo efeito político verificou-se com a perda de poder político do vereador, que se sentiu prejudicado, intimidado e desprestigiado pelo Executivo, o que evidencia uma ameaça a sua representação política, em razão de ter alterado a política do favor e do mando presente no município.

c) O terceiro efeito político transparece através da disputa política entre os vereadores e os representantes da sociedade civil - delegados e con- selheiros -, já que o OP possibilitou o aparecimento e a formação de "novas lideranças locais."

\section{Considerações Finais}

Chamamos a atenção nesse artigo para o fato de que devemos tratar com cuidado a euforia democrá tica em torno das experiências participativas que emergiram no contexto da década de 1990 no auge da hegemonia neoliberal.Tais riscos são enfatizados por Dagnino (2004) como deslocamento na política pela perversão e confluência de projetos distintos - neoliberal e democrático. Essa confluência deve ser pensada também no que se refere ao impacto sobre o governo local e nas 'culturas políticas' nos diferentes municípios brasileiros.

De fato, o orçamento participativo, poderia representar um dos instrumentos gestores de inovação democrática nos municípios que incentivam a participação popular na gestão pública, no fortalecimento do governo local e na accountability. Desta forma traria como resultados administrações mais transparentes e fortalecidas pela participação da população nas decisões sobre políticas públicas, principalmente, sobre a questão orçamentária.

É notório que a questão da emergência desses espaços públicos com os conselhos gestores e o OP no Brasil representam uma aposta democrática fundamental para a construção e a afirmação de direitos na contramão ao projeto neoliberal. Por outro lado, há que se ter cuidado ao analisarmos o significado da participação e do poder de decisão desses novos atores nesse processo. Chamamos a atenção para o risco de que essa participação e esse poder de decisão possam ser despolitizados no enfrentamento da política local, com uma forte prática clientelista, e perder seu conteúdo crítico voltado para o campo dos direitos e da democracia radical.

\section{Referências}

ABERS, R. From Clientelism to Co-operation: Local Government, Participatory Policy, and Civic Organizing in Porto Alegre, Brazil. Politics \& Society, v. 26, n. 4, p. 511-23, 1998. 
AVRITZER, L. Modelos de deliberação democrática: uma análise do orçamento participativo no Brasil. In: SANTOS, B. de S. (Org.). Democratizar a democracia. Rio de Janeiro: Record, 2002, v. 1, p. 01-678.

.; SANTOS, B. de S. Per un ampliamento del canone democratico. In: SANTOS, B. de S. (Org.). Democratizzare la democrazia. Troina: Città Aperta Edizione, 2003, v. 1, p. 1-548.

.; NAVARRO, Z. (Org.). A inovação democrática no Brasil. São Paulo: Cortez, 2003.

.; WAMPLER, B. Públicos participativos: sociedade civil e novas instituições no Brasil democrático. In: COELHO, S. P; NOBRE, M. (Org.). Participação e deliberação. São Paulo: Editora 34, 2004.

BAIRLE, S. G. Um novo princípio ético-político: prática social e sujeito nos movimentos populares urbanos em Porto Alegre nos anos 80. Dissertação (Mestrado em Ciência Política) - Curso de Ciência Política, UNICAMP, São Paulo, 1992.

BARRA MANSA. Prefeitura Municipal de Barra Mansa. Manual do Orçamento Participativo. Barra Mansa, 2000.

em 1996. Barra Mansa, 1996.

Programa de governo para as eleições

BEZERRA, M. A. Em nome das bases: política, favor e dependência pessoal. Rio de Janeiro: Relume-Dumará, 1999.

DAGNINO, E. Sociedade civil, participação e cidadania: de que estamos falando? In: MATO, D. (Coord). Políticas de ciudadania y sociedad civil en tiempos de globalización. Caracas: Faces, Universidad Central de Venezuela, 2004 p. 95-110.

DANIEL, C. Poder local no Brasil urbano. Espaços e Debate, NERU: São Paulo, n. 24, v. 9, p. 25-39, 1988.

DIAS, M. R. Sob o signo da vontade popular: o orçamento participativo e o dilema da Câmara Municipal de Porto Alegre. Belo Horizonte: Editora UFMG, RJ, IUPERJ, 2002.

FEDOZZI, L. Orçamento participativo - Reflexões sobre a experiência de Porto Alegre. Porto Alegre: Tomo Editorial, FASE/IPPUR, 1997.

GENRO, T.; SOUZA, U. O orçamento participativo: a experiência de Porto Alegre. São Paulo: Fundação Perseu Abramo, 1997.

JORNAL DO OP [da] Prefeitura Municipal de Barra Mansa. Barra Mansa, 1998.
RIBEIRO, A. C.; GRAZIA, G. de (Org.). As experiências de orçamento participativo no Brasil - período de 1997-2000. São Paulo: Paz e Terra, 2002.

SANCHES, S. F. Orçamento participativo: teoria e prática. São Paulo: Cortez, 2002.

SANTOS, B. de S. Democratizar a democracia. Os caminhos da democracia participativa. Rio de Janeiro: Civilização Brasileira, 2002.

SILVA, K. M. Construção da 'participação popular': análise comparativa de experiências de participação na discussão pública do orçamento em municípios da região metropolitana de Porto Alegre/RS. Tese (Doutorado em Sociologia) - IFCH, UFRGS, Porto Alegre, 2001.

\section{Notas}

1 Esse artigo é uma versão modificada de parte da minha tese de doutorado em Ciências Sociais Clientelismo, cultura política e democracia: dilemas e desafios da participação popular. A experiência do orçamento participativo da cidade de Barra Mansa, defendida na UNICAMP em fevereiro de 2006.

2 Denominamos o orçamento participativo e os conselhos gestores municipais como novos instrumentos porque eles representaram, após a constituição Federal de 1988, um novo canal de poder decisório para a população participar, interferir e controlar a ação do Estado.

3 Segundo dados do IBGE-Perfil dos Municípios Brasileiros, 2002 -, o país conta com 5.560 municípios, dos quais 21 municípios foram criados em 2001.

4 Dados da Pesquisa do Fórum Nacional da Participação Popular, realizado por Ribeiro e Grazia (2002), apontam a existência de mais de 103 experiências de orçamentos participativos espalhadas pelo Brasil.

5 Podemosindicar.Bairle(1992), Fedozzi (1997), GenroeSouza (1997),Abers (1998), Sanches (2000), Avritzer(2002); Avritzer eNavarro (2003); AvritzereWampler(2004),Avritzere Santos (2002)e Ribeiroe Grazia(2002).

6 Palavras do discurso do prefeito na implementação do OP em outubro de 1997.

7 O poder local é entendido aqui a partir das observações de Daniel (1988,p. 30), ao identificá-lo como "a manifestação de múltiplas expressões sociais de poder, a que correspondem outras tantas culturas políticas, referências para legitimação do poder político e da própria sociedade.”

8 Citaçãode palavras da prefeitaInês Pandeló(1997-2000), registradas em Ata da Câmara de Vereadores, em setembro de 1997. 
9 Retirado do Informativo da PMBM, Ano II, n. 6, publicado emjunhode 1998.

10 A esse respeito indicamos Bezerra(1999).

\section{Angela Vieira Neves}

Doutora em Ciências Sociais pela UNICAMP.

Assistente social

Professora do Departamento de Serviço Social de

Niterói da Universidade Federal Fluminense

Campus do Gragoatá - Bloco "E"

Gragoatá

Niterói - Rio de Janeiro

CEP: 20730-320 